\title{
The first 365 days - on target for a healthy future
}

The Journal of Developmental Origins of Health and Disease is now almost exactly one year old. As its aficionados know, birth weight and weight at the age of 1 year are strong predictors of lifelong health. We are confident that the weight of our journal is on target for a healthy future. The number, range and quality of papers submitted during our first year confirm that the time was ripe for a journal dedicated to $\mathrm{DOHaD}$. The Journal has lived up to its remit to represent the breadth and depth of this field of science, spanning as it does human epidemiology, animal physiology, and cellular and molecular mechanisms. This multi-disciplinary approach is exemplified in the current Issue. Where else would you find papers on the effects of maternal nutrition on gene expression in mice [1], and of fetal growth on kinase signalling pathways in the rat heart [2], side by side with papers on the role of the placenta in programming [3], and on birth outcomes among 30,000 survivors of famine in China [4]?

2010 has brought evidence that $\mathrm{DOHaD}$ concepts are finally influencing public health thinking and policy. We have seen the arrival of 'the first 1,000 days' slogan [5], which recognises that nutrition during the period from conception through pregnancy and the first 2 post-natal years (a total of almost exactly 1,000 days) is critical for deciding a child's future health and capacity. It is accepted that the health and nutrition of mothers and infants have lasting effects on growth, body composition, brain development, educational achievement and earning capacity, and susceptibility to both infectious and chronic non-communicable disease. Despite this growing recognition, we still all too often see early development left out of the equation when considering opportunities for promoting health and preventing disease. The widespread and growing problems of obesity, cardiovascular disease, type 2 diabetes, chronic respiratory disease, osteoporosis and mental illness threaten the ability of health systems to cope, especially in developing and transitioning populations. There is strong evidence that the risk of developing these diseases is determined or influenced by the early life environment. Yet current medical and public health strategies focus almost entirely on treating established disease or secondary prevention in adult life. The scope for primary or even 'primordial' prevention by improving early development remains under-emphasised. This is because there is still a lot of work to do, to quantify the effects of early development on health, to elucidate the mechanisms, and to determine how to support early development to achieve maximal health in different human populations. This will require $\mathrm{DOHaD}$ research in all its diversity, and platforms like the World DOHaD Congress [6] and, of course, this Journal, to bring it all together.
I would like to take the opportunity to thank Michael Ross, Editor-in-Chief of J DOHaD and his Editorial Assistant Antonia Enriquez, for their lion's share, of the work involved in raising this infant Journal successfully through its first Volume. We also owe a debt of gratitude to the authors who have submitted their work, and to the international and multi-disciplinary Associate Editors and Editorial Board, who steer and supervise the progress of each submitted paper through the peer review process. The Journal would especially like to thank all those who have acted as reviewers, ensuring that our publication is of the highest standard. A full list of reviewers is published as a Supplementary File (online only) to this Editorial [Suppl Mat 1]. Finally, it has been a pleasure for us to work with Cambridge University Press, which has achieved the best that professionalism and technology can offer in providing access to the Journal's content, in a beautiful format.

$J \mathrm{DOHaD}$ is open to everyone working in the field, but it is also the flagship publication of the International $\mathrm{DOHaD}$ Society. We therefore urge all members of the Society to give it their continuing support. First and foremost, please continue to submit your papers, from all corners of the $\mathrm{DOHaD}$ field. Think of $J D O H a D$ as the first port of call for your work, and encourage your colleagues to do the same. As you know, the Journal does not yet possess an Impact Factor, or listing in PubMed and the ISI Web of Science. Obtaining these things takes time following the launch of a new journal, and requires us to satisfy a range of criteria from the quality of our content to the punctuality with which each Issue appears. The harsh realities of the research environment mean that we all have to consider the citation opportunities provided by different journals when submitting papers for publication. Suffice it to say that the process of obtaining full listing for $J$ $\mathrm{DOHaD}$ is under way and we are confident of achieving this milestone at the earliest.

What else can you do to support the Journal? If your institution's library does not subscribe to $J \mathrm{DOHaD \text {, }}$ recommend it to your librarian online: http://journals.cambridge.org/recommend_doh. Recommendations from faculty members are the primary influence on librarians' budget decisions, so each one is vital. If you are organising or attending a conference, please e-mail Jo Rennie, the Journal's Marketing Executive, who can send you promotional material: jrennie@cambridge.org. She can also supply J DOHaD web banners for you own websites. Consider including a link to the Journal on the bottom of your e-mail signature: http:// journals.cambridge.org/jdohad. And finally, take advantage of our system for getting e-mail alerts as new articles are published online: http://journals.cambridge.org/doh-alerts. 
Thank you for your help in making $J \mathrm{DOHaD}$ the journal that keeps you up to date and interested in our exciting field of research. We hope that you enjoy this final Issue of our first Volume, and we wish all our readers and contributors a productive and successful 2011.

Caroline Fall Associate Editor and Secretary of the International DOHaD Society

\section{Supplementary Material Reference}

Suppl Mat 1. Fall, C. DOH Referees Acknowledgement 2010.pdf. J Dev Orig Health Dis. 2010; Suppl Mat1 (http:// journals.cambridge.org/doh).

\section{References}

1. Asopa S, Cagampang FR, Anthony FW, et al. Effect of a lowprotein diet during pregnancy on expression of genes involved in cardiac hypertrophy in fetal and adult mouse offspring. J Dev Orig Health Dis. 2010; 1, 370-374.

2. Wadley GD, Wlodek ME, Ng G, et al. Growth restriction before and after birth increases kinase signaling pathways in the adult rat heart. J Dev Orig Health Dis. 2010; 1, 375-384.

3. Barker DJP, Thornburg KL, Osmond C, Kajantie E, Eriksson JG. Beyond birthweight: the maternal and placental origins of chronic disease. J Dev Orig Health Dis. 2010; 1, 360-364.

4. Huang C, Li Z, Venkat Narayan KM, Williamson DF, Martorell R. Bigger babies born to women survivors of the 1959-1961 Chinese famine: a puzzle due to survival selection? J Dev Orig Health Dis. 2010; 1, 411-417.

5. 1,000 Days. www.thousanddays.org (accessed $6^{\text {th }}$ December 2010).

6. World DOHaD Congress 2011. www.dohad2011.org (accessed $6^{\text {th }}$ December 2010). 